\title{
Sexual dysfunction in males with chronic hepatitis $C$ and antiviral therapy: interferon-induced functional androgen deficiency or depression?
}

\author{
M R Kraus, A Schäfer, T Bentink, M Scheurlen, B Weissbrich², \\ O Al-Taie and J Seufert ${ }^{1}$ \\ Department of Gastroenterology and Hepatology, Medizinische Poliklinik, University of Würzburg, Klinikstrasse 6-8, D-97070 Würzburg, Germany \\ ${ }^{1}$ Division of Metabolism, Endocrinology and Molecular Medicine, Medizinische Poliklinik, University of Würzburg, Würzburg, Germany \\ ${ }^{2}$ Institute for Virology and Immunobiology, University of Würzburg, Versbacher Strasse 7, D-97078 Würzburg, Germany \\ (Requests for offprints should be addressed to M R Kraus; Email: kraus_m@klinik.uni-wuerzburg.de)
}

\begin{abstract}
Decrease of libido and erectile dysfunction are reported by male patients during antiviral therapy of chronic hepatitis C, but therapy-associated underlying factors for sexual dysfunction are not well defined. To assess putative contributions of interferon-induced sex hormone changes to sexual dysfunction, we prospectively investigated changes in free testosterone, total testosterone, dehydroepiandrosterone sulfate, prolactin, sex hormone-binding globulin, FSH and LH levels and psychometric selfassessment scores in 34 male patients treated with interferon alfa-2b (5 MIU three times weekly) $(n=19)+$ ribavirin $(n=15)$ for 6-12 months. Depression was measured by the Hospital Anxiety and Depression Scale. Sexual dysfunction was evaluated by the Symptom
\end{abstract}

Checklist 90 Item Revised and a five-point rating scale assessing sexual arousal disorder. Free and total testosterone decreased significantly during antiviral therapy in close correlation with libido/sexual function. Depression scores increased during therapy and were also significantly associated with sexual dysfunction. However, androgen levels displayed no significant correlation with depression. These results suggest that interferon-induced decrease in sexual function is associated - but not causally related with both androgen reduction and increased depressive symptoms. These findings may affect care for male hepatitis $\mathrm{C}$ patients during interferon therapy.

Journal of Endocrinology (2005) 185, 345-352

\section{Introduction}

Interferon alfa is therapeutically used, e.g. in malignant diseases and chronic viral hepatitis. Recombinant human interferon alfa has proven its antiviral effect in several licensing trials (McHutchison et al. 1998, Manns et al. 2001, Fried et al. 2002, McHutchison \& Fried 2003) representing currently the standard treatment of chronic hepatitis C. Sustained virological response is achieved at present in about $50 \%$ of patients treated with a combination of peginterferon alfa and ribavirin for up to 12 months (Manns et al. 2001, Fried et al. 2002).

However, interferon alfa treatment is still unsatisfactory with respect to its profile of side-effects. Psychiatric side-effects (especially depression) are frequently seen in systemic therapy with human recombinant interferon alfa (Kraus et al. 2003). There are known hormonal effects of interferon alfa (e.g. on thyroid hormone metabolism (Corssmit et al. 1995)) - however, the extent of hormonal changes during interferon alfa therapy of chronic hepatitis C for up to 1 year is still not clear.

In addition, potential associations of hormonal changes with psychiatric symptoms such as depression or sexual dysfunction especially in male patients have yet to be documented. Occasionally, male hepatitis $\mathrm{C}$ patients on interferon alfa therapy report on noticeable symptoms such as sexual dysfunction or libido loss (Soto Alvarez et al. 1991). This may indicate a specific side-effect of interferon therapy, which possibly reduces quality of life and additionally adherence to antiviral therapy. Until now, it is not clear whether this is solely due to increased depression or whether this can be partially explained by hormonal changes.

Therefore, we prospectively investigated timing and intensity of psychiatric symptoms (especially depression), sexual satisfaction and hormonal changes (especially serum androgen levels) induced by therapy with recombinant human interferon alfa- $2 \mathrm{~b}$ in male patients with chronic hepatitis C. 


\section{Subjects and Methods}

\section{Subjects}

Thirty-seven consecutive male outpatients were included in our study. Chronic hepatitis $\mathrm{C}$ was diagnosed at our institution or the patients had been referred for antiviral therapy of known chronic hepatitis C.

All patients had documented antibodies to hepatitis $C$ virus (HCV) and circulating HCV-RNA as measured by RT-PCR (Cobas Amplicor HCV Monitor test; Roche Diagnostics).

Exclusion criteria were: age under 18 or above 65 years, coinfections (HBV or HIV), severe internal diseases (e.g. cancer, ischemic heart disease, autoimmune disease), psychiatric illness (severe depression or psychosis etc.), active i.v. drug use or alcohol abuse, obvious intellectual impairment or insufficient knowledge of the German language. In addition, the use of antidepressants (especially with dopaminergic effects) was an exclusion criterion due to their known interference with serum hormone levels.

If liver cirrhosis was already present, it had to be well compensated (Child A, Child-Pugh Classification).

All patients gave informed consent to study participation before enrollment. The study protocol was approved by the ethics committee (for medical research) of Würzburg University in accordance with the Declaration of Helsinki.

\section{Study design}

The study was designed as a prospective longitudinal single-center study.

Three out of $37(8 \cdot 1 \%)$ patients could not be included in the final evaluation and statistical analysis: two patients terminated therapy prematurely within the first 3 months because of intolerable side-effects (depression, flu-like symptoms), and one patient withdrew his consent to study participation. Thirty-four patients finally completed the study.

According to the corresponding recommendations in Germany during the recruitment phase, patients were treated with interferon alfa-2b (as opposed to pegylated interferon representing the current therapy standard) alone $(n=19)$ or combination therapy (starting in August 1998, $n=15)$ with interferon alfa- $2 \mathrm{~b}$ plus ribavirin.

The interferon alfa-2b (Intron A) used in the study was obtained from Essex Pharma, Munich, Germany, a subsidiary of Schering-Plough, Kenilworth, NJ, USA.

In case of virological response, $5 \mathrm{MIU}$ interferon alfa$2 \mathrm{~b} \pm$ ribavirin three times weekly were given for up to 12 months. Patients on antiviral combination therapy with interferon alfa-2b and ribavirin received oral ribavirin (800-1200 mg daily).

In all eligible patients, psychometric scores and laboratory data were obtained before therapy (t1), after 4 weeks (t2) and 3-4 months (t3) of treatment as well as 4-6 weeks (t4) after termination of therapy. As there were several patients (genotype 2 or 3 ) with a total treatment period of 6 months, we did not use an evaluation time point during interferon therapy after $\mathrm{t} 3$.

Blood samples were obtained during the patients' medical visits at time points $\mathrm{t} 1-\mathrm{t} 4$ for measurement of blood count, transaminases, HCV-RNA and hormone serum levels. Genotype identification and liver biopsy (staging and grading: inflammation, fibrosis, cirrhosis) were performed once before therapy. The mode of infection was documented.

\section{Psychometric instruments/questionnaires}

Depression: the Hospital Anxiety and Depression Scale (HADS) Depression was assessed by the wellvalidated HADS, German version, as published by Herrmann et al. (1995). HADS is a 14-item questionnaire with the dimensions anxiety and depression. All items exclusively refer to the emotional state and do not reflect somatic symptoms (Herrmann et al. 1995).

Self-assessment of male sexual dysfunction Libido/ sexual satisfaction was assessed by the SCL-90-R, Symptom Checklist-90 Items Revised (Derogatis 1975, German version, as published by Franke (1995)) by item 5. The questionnaire contains one item ('loss of sexual interest or pleasure') exclusively referring to libido. In addition, we used a (self-developed) five-point Likert rating scale ('no limitation' to 'complete dysfunction'; $0-4$ points) for the corresponding self-assessment.

\section{Assays/serum hormone levels}

Blood samples were immediately centrifuged at $4{ }^{\circ} \mathrm{C}$ and serum supernatant frozen at $-20^{\circ} \mathrm{C}$. All analyses were performed in duplicates by analytical personnel. Commercially available high-sensitivity immunoassays were used according to the manufacturer's protocols, and each subject's samples were run concurrently. Unless otherwise stated, all coefficients of variation for interassay and intraassay variation were below $8 \cdot 5 \%$. For all assays it has been confirmed that the presence of bilirubin in concentrations up to $100 \mathrm{mg} / \mathrm{l}$, hemoglobin (hemolysis) up to $300 \mathrm{mg} / \mathrm{dl}$ and triglycerides up to $1000 \mathrm{mg} / \mathrm{dl}$ do not interfere with precision of the assays.

Serum levels of the following hormones were measured: testosterone (free and total testosterone), sex hormonebinding globulin (SHBG), prolactin, dehydroepiandrosterone sulfate (DHEAS), luteinizing hormone (LH) and follicle stimulating hormone (FSH).

The normal range for each parameter reflects the intervals specifically determined by the analytical laboratory of the institution. 
Table 1 Patient characteristics

\begin{tabular}{|c|c|c|c|c|}
\hline & $\begin{array}{l}\text { All patients } \\
(n=34)\end{array}$ & $\begin{array}{l}\text { Interferon alfa-2b monotherapy } \\
(n=19)\end{array}$ & $\begin{array}{l}\text { Interferon afla-2b + ribavirin } \\
(n=15)\end{array}$ & $P$ - value \\
\hline \multicolumn{5}{|l|}{$\begin{array}{l}\text { Sociodemographic and } \\
\text { biomedical factors }\end{array}$} \\
\hline Age (range) & $36 \cdot 9 \pm 1 \cdot 4(19-52)$ & $37 \cdot 0 \pm 1 \cdot 6(22-47)$ & $36 \cdot 9 \pm 2 \cdot 6(19-52)$ & $0 \cdot 963$ \\
\hline Acquisition mode & & & & 0.912 \\
\hline Unknown & $10(29 \cdot 4 \%)$ & $6(31 \cdot 6 \%)$ & $4(26 \cdot 7 \%)$ & \\
\hline Former IVDU & $19(55 \cdot 9 \%)$ & $10(52 \cdot 6 \%)$ & $9(60 \cdot 0 \%)$ & \\
\hline Post-transfusion & $5(14 \cdot 7 \%)$ & $3(15 \cdot 8 \%)$ & $2(13 \cdot 3 \%)$ & \\
\hline Virus genotype* & & & & $0 \cdot 704$ \\
\hline Genotype 1 & $21(61 \cdot 8 \%)$ & $12(63 \cdot 2 \%)$ & $9(60 \cdot 0 \%)$ & \\
\hline Genotype 2 & $3(8 \cdot 8 \%)$ & $1 \quad(5 \cdot 3 \%)$ & $2(13 \cdot 3 \%)$ & \\
\hline Genotype 3 & $10(29 \cdot 4 \%)$ & $6(31 \cdot 5 \%)$ & $4(26 \cdot 6 \%)$ & \\
\hline Liver biopsy/liver damage & & & & $0 \cdot 316$ \\
\hline Hepatitis only & $17(51 \cdot 6 \%)$ & $9(50 \cdot 0 \%)$ & $8(53 \cdot 3 \%)$ & \\
\hline Fibrosis & $8(24 \cdot 2 \%)$ & $6(33 \cdot 3 \%)$ & $2(13 \cdot 3 \%)$ & \\
\hline Cirrhosis & $8(24 \cdot 2 \%)$ & $3(16 \cdot 7 \%)$ & $5(33 \cdot 4 \%)$ & \\
\hline
\end{tabular}

${ }^{*}$ In one patient treated with interferon alfa-2b monotherapy, liver biopsy was declined. Presented $P$-values were obtained by $t$-tests for independent samples (continuous data) or chi-square test (catecorical data) respectively. IVDU, intravenous drug use.

The following assays were used. Total testosterone was assayed by a solid-phase, competitive chemiluminescent enzyme immunoassay on an Immulite 1000 Analyzer (Diagnostic Products Corporation, Los Angeles, CA, USA) with intraassay variability (coefficient of variation) $<6 \%$ and interassay variability $<7 \cdot 5 \%$. The expected normal range for men aged 20-55 years is 270-1070 ng/ dl. Free testosterone was assayed by an RIA (Diagnostic Systems Laboratories, Sinsheim, Germany) with intraassay variability (coefficient of variation) $<7 \cdot 5 \%$ and interassay variability $<6 \%$. The expected normal range for men aged 20-55 years is $14-42 \mathrm{ng} / 1$. In this study, serum testosterone levels are analyzed at a single time point in duplicates and reflect non-fasting serum concentrations. SHBG was assayed by an ELISA (Diagnostic Systems Laboratories). Prolactin, DHEAS, LH and FSH were assayed by solidphase, competitive chemiluminescent enzyme immunoassays on an Immulite 1000 Analyzer. The expected normal ranges for men aged 20-55 years are 53$360 \mathrm{mIU} / \mathrm{L}$ for prolactin, $80-560 \mu \mathrm{g} / \mathrm{dl}$ for DHEAS, 0.8-7.6 IU/1 for LH and 1·5-14 IU/1 for FSH.

Serum albumin levels were monitored for all study patients throughout the study period.

\section{Statistical analysis}

Data were registered and analyzed using the Statistical Package for Social Sciences (SPSS for Windows, German version $11 \cdot 5 \cdot 1$ (SPSS 2002)).

All tests of significance were two-tailed. $P$ values of $<0.05$ were considered statistically significant. Because of the explorative character of the study we did not consider alfa adjustment in multiple comparisons.
Descriptive analysis Results describing quantitative measures are expressed as means \pm S.D. or \pm S.E. Qualitative variables are presented as counts and percentages.

Tests of significance Comparison of variables representing categorical data was performed using the chi-squared test.

Group means of dependent samples (e.g. time course of continuous variables) were compared by means of repeated-measures ANOVA (general linear model procedure, repeated-measures design). Corresponding contrasts were analyzed by paired $t$-tests.

Pearson's correlation was used when appropriate (assessment of associations between quantitative variables).

\section{Results}

\section{Study population}

Table 1 shows baseline characteristics of the 34 patients who were included in the final evaluation.

There were no significant differences in sociodemographic or biomedical parameters between both subgroups (treatment with interferon alfa monotherapy or combination therapy with interferon alfa- $2 b$ and ribavirin). The (low) mean age of less than 40 years $(36.9 \pm 1 \cdot 4$; range: 19-52 years) in our study sample is remarkable, because it is known that usually symptoms of male sexual dysfunction/arousal disorder are age-related (Martin 1979). Thus, advanced age as a possible confounding factor in the evaluation of libido loss can be considered negligible in this study. 


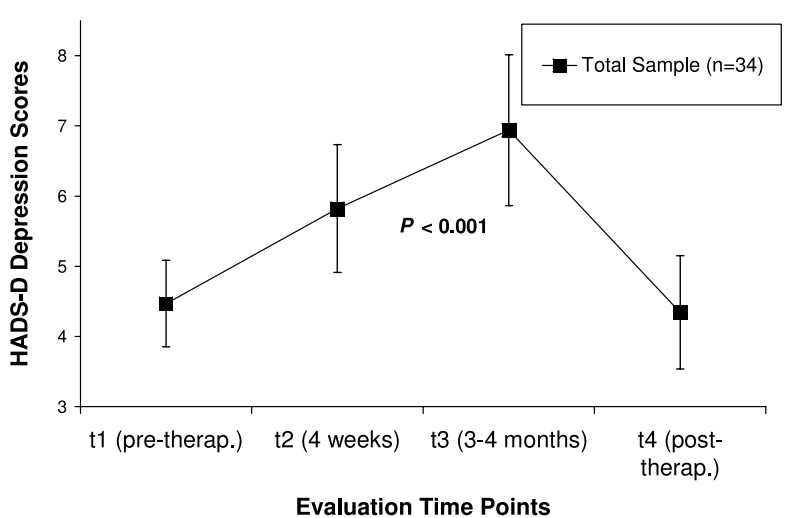

Figure 1 Time course of mean HADS depression scores ( \pm S.E.M.) in 34 male hepatitis $C$ patients before, during and after interferon alfa therapy.

\section{Clinical features}

Clinical side-effects of interferon alfa - especially with respect to psychiatric symptoms - have previously been reported (Kraus et al. 2003). In accord with these results, HADS depression scores increased significantly (and reversibly after therapy) during treatment with interferon alfa-2b. Corresponding results are displayed in Fig. 1.

The SCL-90-R depression subscale confirmed these findings.

\section{Self-assessment of sexual dysfunction and libido loss}

Scores for libido self-assessment declined significantly during the course of interferon alfa therapy. Both SCL90-R (item 5: 'loss of sexual interest or pleasure'; $P<0.001)$ and the five-point Likert scale $(P<0.001)$ increased significantly over time during therapy with interferon alfa- $2 \mathrm{~b}$ (and ribavirin). Corresponding results are displayed in Fig. 2.

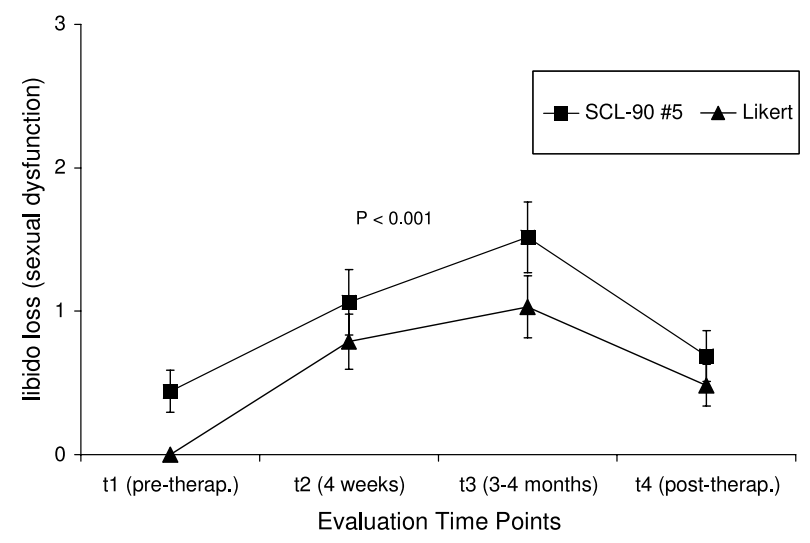

Figure 2 Time course of mean self-assessment scores ( \pm S.E.M.) of libido loss (SCL-90-R item 5; Likert scale) in 34 male hepatitis C patients before, during and after interferon alfa therapy (higher values represent deterioration).
Both items (SCL-90-R item 5 and the self-developed Likert rating scale) displayed high correlation at $\mathrm{t} 3$, after 3-4 months of antiviral therapy (Pearson correlation coefficient $r=0.793 ; P<0 \cdot 001)$.

Additionally, we performed a subgroup analysis to get insight into whether the observed loss of sexual interest was common in our study sample or restricted to a subgroup of male patients.

There were 15 out of 34 patients (44.11\%) indicating a decline in sexual interest/satisfaction in both administered scales and 22 out of 34 male hepatitis C patients $(64 \cdot 71 \%)$ confirmed libido loss on at least one of the psychometric scales (comparison between evaluation time points $t 1$ and $\mathrm{t} 3$ ).

The type of interferon therapy administered (monotherapy vs combination therapy with additional ribavirin) had no significant effect on the incidence rate of symptoms of libido loss during antiviral therapy (chi square test; $P>0 \cdot 350)$.

\section{Effect of interferon alfa-2b therapy on (sex) hormone levels}

SHBG, LH Serum levels of SHBG $(P=0 \cdot 614)$ and LH $(P=0.810)$ did not change significantly over time in our study group (repeated-measures ANOVA; $P>0 \cdot 05$ ). Albumin levels were within the normal range throughout the study period (data not shown).

Testosterone By means of repeated-measures ANOVA, we were able to detect the following significant hormone changes over time. First, we observed a marked decrease over time of testosterone serum levels (Fig. 3). As shown in Fig. 3A, compared with baseline values, free testosterone levels declined significantly during therapy with interferon $a l f a-2 b$ and ribavirin (repeated-measures ANOVA: main effect time: $P<0 \cdot 001)$. Four weeks after the end of therapy $(\mathrm{t} 4)$, this reduction was still persistent.

Interferon-associated testosterone deficiency was also significant for total testosterone levels $(P<0 \cdot 001$; Fig. 3B). However, there was a minimum of observed mean total testosterone concentration at $\mathrm{t} 3$, with a clear tendency towards reversibility after the end of interferon treatment $(\mathrm{t} 4)$.

DHEAS, prolactin DHEAS serum concentrations declined significantly $(P=0.012)$ during interferon alfa-2b medication with a minimum already at $\mathrm{t} 2,4$ weeks after initiation of antiviral therapy (Fig. 4). The respective values tended towards restoration of baseline data at $\mathrm{t} 4$, about 4 weeks after termination of antiviral medication.

During the study period, prolactin blood concentrations rose significantly to a maximum at time point $t 3$ $(P=0 \cdot 041)$. This increase was reversible after the end of interferon alfa-2b therapy (Fig. 5). 
A.

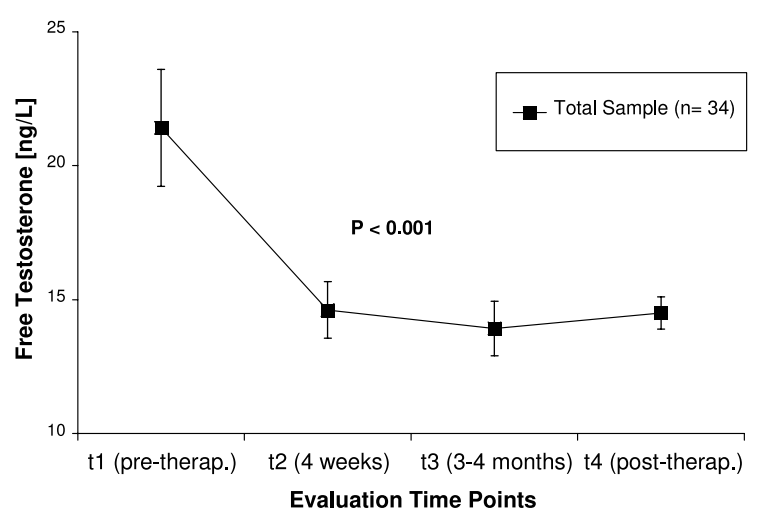

B.

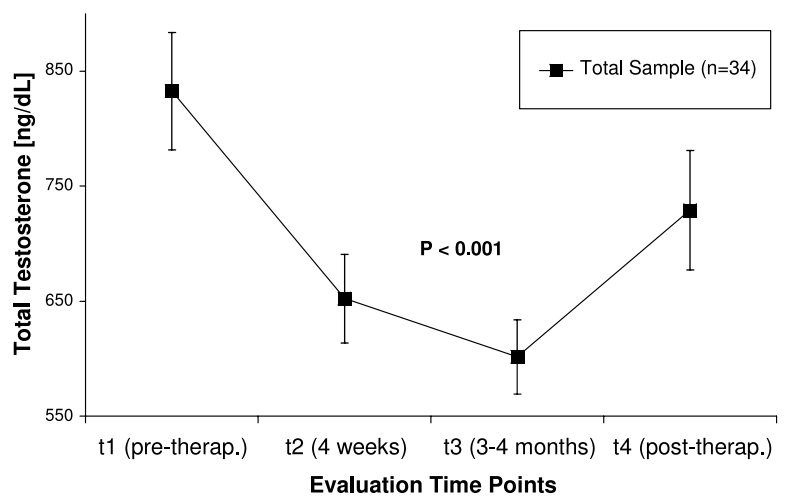

Figure 3 Time course of mean serum testosterone levels ( \pm S.E.M.) in 34 male hepatitis $C$ patients before, during and after interferon alfa therapy. (A) Free testosterone (ng/l; to convert values to nmol/l, multiply by $0 \cdot 347)$. (B) Total testosterone ( $\mathrm{ng} / \mathrm{dl}$; to convert values to $\mathrm{nmol} / \mathrm{l}$, multiply by $0 \cdot 0347$ ).

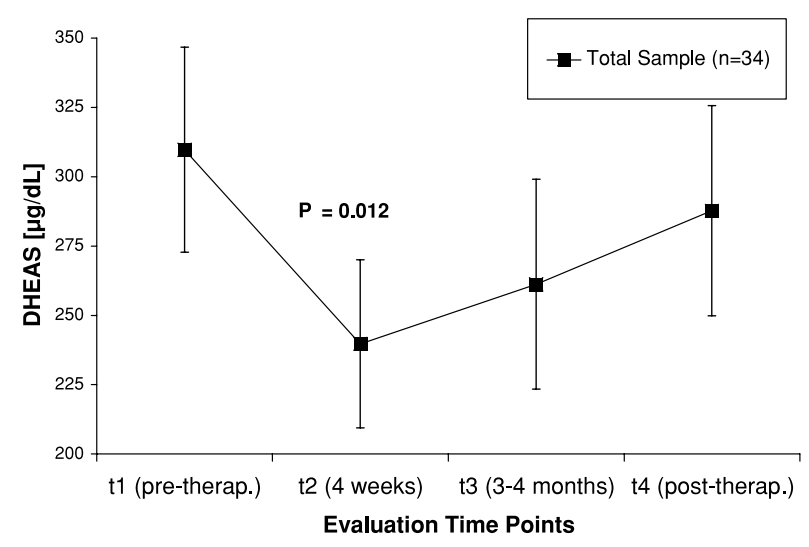

Figure 4 Time course of mean DHEAS serum levels ( \pm S.E.M.) in 34 male hepatitis $\mathrm{C}$ patients before, during and after interferon alfa therapy (measurement unit: $\mu \mathrm{g} / \mathrm{dl}$; to convert values to $\mu \mathrm{mol} / \mathrm{l}$, multiply by 0.02714).

Both hormone serum concentrations did not fully reach baseline levels after the end of therapy - however, post-hoc comparisons (pre- vs post-therapy levels) were not statistically significant.

Relationship between libido loss, interferon-induced depressive symptoms and hormonal changes during interferon alfa- $2 b$ therapy

As male sexual arousal disorder may be affected by both hormonal and psychological factors, we analyzed intercorrelations between therapy-associated libido loss and increase in depression scores or changes in hormone levels respectively. The following analyses are based on observed changes between $\mathrm{t} 1$ (baseline data) and t3, 3-4 months after initiation of antiviral therapy (Table 2).

As expected, interferon-associated sexual dysfunction was significantly associated with therapy-induced depression $(r=0 \cdot 64 ; P<0 \cdot 001)$. Therefore, symptoms of male sexual arousal disorder during interferon therapy

Table 2 Intercorrelations between libido loss, interferon-induced depressive symptoms and hormonal changes during interferon alfa-2b therapy $(\mathrm{t} 1-\mathrm{t} 3)$

\begin{tabular}{|c|c|c|c|}
\hline & Parameter 2 & $\begin{array}{l}\text { Correlation } \\
\text { coefficient } \\
\text { (Pearson's r) }\end{array}$ & $P$-value \\
\hline \multicolumn{4}{|l|}{ Parameter 1} \\
\hline Sexual dysfunction & Depression & $0.47-0.64^{*}$ & $\leq 0.006$ \\
\hline Free testosterone & Sexual dysfunction & $-0 \cdot 42^{*}$ & 0.038 \\
\hline Prolactin & Free testosterone & $-0 \cdot 21$ & 0.320 \\
\hline Free testosterone & Depression & $-0 \cdot 27$ & 0.209 \\
\hline
\end{tabular}




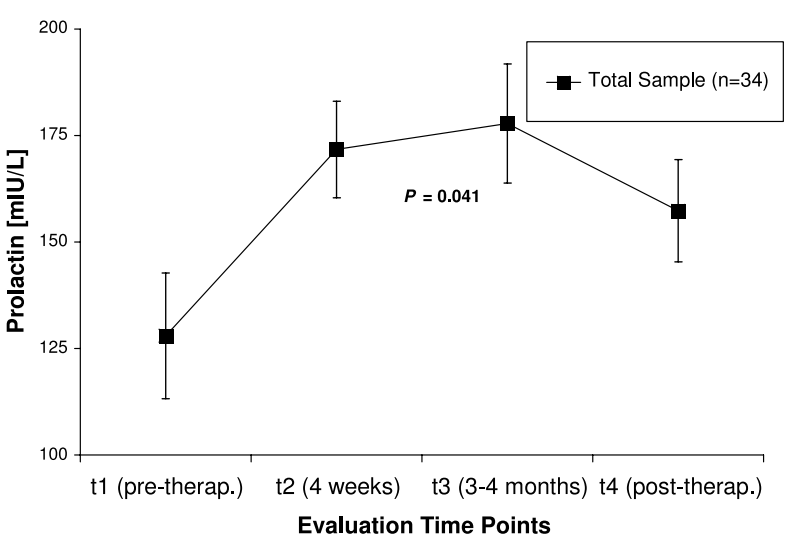

Figure 5 Time course of mean prolactin serum levels ( \pm S.E.M.) in 34 male hepatitis $C$ patients with interferon alfa therapy (measurement unit: $\mathrm{mlU} / \mathrm{l}$; to convert values to $\mathrm{pmol} / \mathrm{l}$, multiply by 2.0508).

can be partially explained by underlying depressive sideeffects.

However, there is also a significant negative correlation between free testosterone concentrations during therapy and sexual dysfunction scores at $\mathrm{t} 3(r=-0 \cdot 42 ; P=0 \cdot 038)$. Therefore, to some degree, decreased levels of free testosterone are linked with symptoms of male sexual arousal disorder. Rise of prolactin serum levels was not significantly associated with free testosterone reduction in our study $(r=-0 \cdot 21 ; P>0 \cdot 05$; see Table 2$)$. These results indicate an effect of interferon therapy on male gonadal steroid biosynthesis independent from control actions of prolactin on androgen production. Moreover, interferonassociated depressive symptoms and changes in sex hormone levels are not directly linked $(|\mathrm{r}|<0 \cdot 27 ; P>0 \cdot 05)$ in male hepatitis $\mathrm{C}$ patients during interferon alfa therapy (Table 2).

\section{Discussion}

In addition to previously described psychiatric side-effects (Kraus et al. 2003, 2005a,b, Loftis \& Hauser 2004), we focused in this study on the assessment of symptoms of sexual arousal disorder (APA 1994) and sexual dysfunction in response to interferon alfa- $2 \mathrm{~b}$ administration in antiviral treatment of male patients with chronic hepatitis C. In addition, we were particularly interested in androgen changes, alterations of the pituitary-testicular axis and adrenal gland function that may occur during interferon treatment of patients with chronic hepatitis C.

The patients in our study showed significantly increased depression scores during the treatment period, and we could also confirm previous patients' reports on interferonassociated libido loss (Soto Alvarez et al. 1991).

The assessment of interferon-induced changes in sex hormone serum levels has been so far limited to small studies (Barreca et al. 1993, Kauppila et al. 1997, Corssmit et al. 2000, Weidinger et al. 2002), case reports or animal models (Hibi et al. 1997, Montor et al. 1998).

In accord with Barreca et al. (1993) and Corssmit et al. (2000), we observed a significant decline of free and total testosterone serum concentrations within the normal range over time. As testicular function is known to be controlled by gonadotropins (LH, FSH) and is affected by prolactin, we evaluated the time course and concentrations of gonadotropins and prolactin. LH levels (as well as FSH serum concentrations) were not significantly affected during interferon alfa- $2 b$ treatment. Therefore, we assume that the observed testosterone decrease is not mediated by alteration of the pituitary-testicular axis. This, however, cannot be entirely excluded as gonadotropin secretion pulsatility was not analyzed.

An explanation for the apparent discrepancy between total and free testosterone levels at $\mathrm{t} 4$ remains open. We confirmed, however, that differences are not due to changes in SHBG levels. This is consistent with the findings of Corssmit et al. (2000). We are aware that the best measures for bioavailable testosterone are represented by either concentrations of free testosterone measured by equilibration dialysis assays or free testosterone calculated from albumin and SHBG levels (Christ-Crain et al. 2004a). However, we believe that in this particular study, direct measurement of free testosterone is equally representative (of male androgen status) because it has been demonstrated that within the physiological range of 40$50 \mathrm{~g} / 1\left(5 \cdot 8-7 \cdot 2 \times 10^{-4} \mathrm{~mol} / \mathrm{l}\right)$ of albumin binding protein concentrations do not significantly affect free testosterone levels (Vermeulen et al. 1999). As indicated, in our study the patients' albumin levels stayed within the normal range throughout the whole evaluation time.

Elevated levels of prolactin are associated with sexual dysfunction, such as reduced libido, erectile dysfunction, diminished ejaculate volume and oligospermia (Spollen et al. 2004). In our study, mean serum prolactin levels were significantly increased during interferon therapy. As it has been demonstrated that the duration and frequency of prolactin secretory bursts from the pituitary are independent from gonadal steroid plasma levels in women and in men (Genazzani et al. 1994), we assume that the observed increase in mean serum prolactin values is not secondary to alterations in gonadal steroid concentrations. Rather we may speculate that interferon therapy either directly affected lactotrope cells in the pituitary, or hypothalamic factors which control prolactin secretion, or both. Elevated serum levels of prolactin during interferon therapy, however, did not significantly correlate with reductions in free testosterone serum concentrations. Therefore, we conclude that prolactin elevation did not contribute to reduced testosterone concentrations and impairment of libido.

In this context, it is important to add that none of the hepatitis $\mathrm{C}$ patients in our study received antidepressant 
medication known to exert dopaminergic effects as a confounding factor in the evaluation and interpretation of increased prolactin levels during interferon alfa- $2 b$ medication.

A marked association between the androgen-precursor DHEA and libido has been demonstrated in females (Arlt et al. 1999). Therefore, we monitored DHEAS levels before, during and after interferon therapy. The reversible decline of DHEAS serum concentrations during antiviral treatment may be explained either by direct effects on the adrenal cortex or by indirect mechanisms involving the adrenocorticotropic hypothalamic-hypophysealadrenal axis via corticotropin-releasing hormone/ adrenocorticotropin. Alternatively, the decline of serum DHEAS in parallel with the observed reductions in total and free testosterone values during interferon therapy may be due to direct affects on the testes in the male patients.

The sexual arousal disorder in our study population was linked to both interferon-induced depressive symptoms and serum free testosterone decline (confirming the results of studies that did not find a significant correlation between total testosterone and symptoms of hypogonadism (Christ-Crain et al. 2004b)). However, we found no direct link between sex hormone changes and depression. This implies that both factors (interferon-induced depression and functional androgen deficiency) may independently affect the extent of male sexual dysfunction in patients with chronic hepatitis $\mathrm{C}$ and therapy with interferon alfa-2b. It is important to note that we do not postulate a causative relationship for each single factor (depression, androgen deficiency) - in contrast we propose that both may be permissive with respect to symptoms of sexual dysfunction.

As it is known that relatively low androgen levels generally suffice for normal sexual function, the results of the study do not allow us to define low testosterone serum concentrations as the main cause for sexual dysfunction in the study population. These may, however, represent among others, such as depression, a permissive factor for libido loss.

There are several limitations in our study that have to be kept in mind when drawing conclusions from the findings. Hormonal changes associated with interferon alfa- $2 b$ therapy were within the normal ranges throughout the evaluation period and therefore have to be interpreted with care. Sample size in our study does not exceed 34 male patients, although the sample population was quite homogeneous and target variables are clear. Therefore, from a statistical point of view this specific sample size provides enough power to detect relevant changes of target variables. Further limitations include the fact that conventional interferon alfa- $2 \mathrm{~b}$ has been used (as opposed to pegylated forms representing the current therapy standard) and that information on sexual dysfunction was obtained by a psychometric instrument that is not validated or referenced with larger study populations.
In summary, we found that treatment with recombinant interferon alfa-2b in male patients with chronic hepatitis $\mathrm{C}$ is associated with functional androgen deficiency. This decline in testosterone is partially linked to therapyinduced symptoms of libido loss and may be due to direct effects of interferon on the gonads or effects on hypothalamic regulatory centers. However, there is an even stronger correlation between symptoms of sexual arousal disorder and interferon-induced depression in these patients.

Subsequent studies should include larger sample sizes (anticipated alfa-level adjustment and corresponding sample size calculations) as well as specific hypothesisdriven analyses based on the presented findings.

In clinical practice, during the workup of patients with chronic hepatitis $\mathrm{C}$ it could be helpful to perform baseline hormone screening prior to the initiation of interferon therapy. Potential interferon-associated symptoms of libido loss and therefore reduced quality of life could hence be better put into context during treatment period (depression vs hormonal changes).

\section{Acknowledgements}

We would like to thank the hormone laboratory staff, especially Ms Luitgard Kraus, for expert technical assistance.

\section{Funding}

This study was supported in part by an unrestricted grant of Essex Pharma, Munich, Germany (a subsidiary of Schering-Plough, Kenilworth, NJ, USA). M R K is a member of the Scientific Advisory Board of Essex Pharma, and has served on speakers bureaus for Shering-Plough and Essex Pharma.

\section{References}

APA 1994 Diagnostic and Statistical Manual of Mental Disorders, Fourth Edition: DSM-IV, edn 4. Washington DC: American Psychiatric Association.

Arlt W, Callies F, van Vlijmen JC, Koehler I, Reincke M, Bidlingmaier M, Huebler D, Oettel M, Ernst M, Schulte HM et al. 1999 Dehydroepiandrosterone replacement in women with adrenal insufficiency. New England Journal of Medicine 341 1013-1020.

Barreca T, Picciotto A, Franceschini R, Varagona G, Garibaldi A, Valle F, Cataldi A, D'Agostino S \& Rolandi E 1993 Sex hormones and sex hormone-binding globulin in males with chronic viral hepatitis during recombinant interferon-alpha $2 \mathrm{~b}$ therapy. Journal of Interferon Research 13 209-211.

Christ-Crain M, Meier C, Huber P, Zimmerli L, Trummler M \& Muller B 2004a Comparison of different methods for the measurement of serum testosterone in the aging male. Swiss Medical Weekly 134 193-197. 
Christ-Crain M, Mueller B, Gasser TC, Kraenzlin M, Trummler M, Huber P \& Meier C $2004 b$ Is there a clinical relevance of partial androgen deficiency of the aging male? Journal of Urology 172 624-627.

Corssmit EP, Heyligenberg R, Endert E, Sauerwein HP \& Romijn JA 1995 Acute effects of interferon-alpha administration on thyroid hormone metabolism in healthy men. Journal of Clinical Endocrinology and Metabolism 80 3140-3144.

Corssmit EP, Endert E, Sauerwein HP \& Romijn JA 2000 Acute effects of interferon-alpha administration on testosterone concentrations in healthy men. European Journal of Endocrinology 143 371-374.

Franke GH 1995 SCL-90-R Symptom-Checkliste von Derogatis-Deutsche Version (Testmappe mit Handanweisung, 5 Frageboegen, 5 Auswertungsboegen und 5 Boegen Graphisches Auswertungsschema). Symptom Check List 90 Items Revised (LR Derogatis 1977) - German version/author. Weinheim: Beltz.

Fried MW, Shiffman ML, Reddy KR, Smith C, Marinos G, Goncales FL Jr, Haussinger D, Diago M, Carosi G, Dhumeaux D et al. 2002 Peginterferon alfa-2a plus ribavirin for chronic hepatitis $\mathrm{C}$ virus infection. New England Journal of Medicine 347 975-982.

Genazzani AD, Petraglia F, Volpogni C, Forti G, Surico N \& Genazzani AR 1994 The duration of prolactin secretory bursts from the pituitary is independent from both prolactin and gonadal steroid plasma levels in women and in men. Journal of Endocrinological Investigation 17 83-89.

Herrmann C, Buss U \& Snaith RP 1995 HADS-D. Hospital Anxiety and Depression Scale-Deutsche Version. Ein Fragebogen zur Erfassung von Angst und Depressivität in der somatischen Medizin. Bern: Huber.

Hibi H, Yokoi K \& Yamamoto M 1997 Effects of alpha-interferon on sperm production, concentration, and motility in the rat. International Journal of Urology 4 603-607.

Kauppila M, Koskinen P, Remes K, Viikari J \& Irjala K 1997 Hypothalamic-pituitary axis remains intact after interferon-alpha treatment in hematologic diseases. Journal of Interferon and Cytokine Research 17 543-550.

Kraus MR, Schafer A, Faller H, Csef H \& Scheurlen M 2003 Psychiatric symptoms in patients with chronic hepatitis $\mathrm{C}$ receiving interferon alfa-2b therapy. Journal of Clinical Psychiatry 64 708-714.

Kraus MR, Schafer A, Al-Taie O \& Scheurlen M 2005a Prophylactic SSRI during interferon alpha re-therapy in patients with chronic hepatitis $\mathrm{C}$ and a history of interferon-induced depression. Journal of Viral Hepatitis 12 96-100.
Kraus MR, Schafer A, Wissmann S, Reimer P \& Scheurlen M $2005 b$ Neurocognitive changes in patients with hepatitis $C$ receiving interferon alfa-2b and ribavirin. Clinical Pharmacology and Therapeutics 77 90-100.

Loftis JM \& Hauser P 2004 The phenomenology and treatment of interferon-induced depression. Journal of Affective Disorders $\mathbf{8 2}$ 175-190.

Manns MP, McHutchison JG, Gordon SC, Rustgi VK, Shiffman M, Reindollar R, Goodman ZD, Koury K, Ling M \& Albrecht JK 2001 Peginterferon alfa-2b plus ribavirin compared with interferon alfa-2b plus ribavirin for initial treatment of chronic hepatitis $C: a$ randomised trial. Lancet 358 958-965.

Martin CE 1979 Sexual activity in the aging male. In Handbook of Sexology, pp 813-824. Eds J Money \& H Musaph. New York: Elsevier.

McHutchison JG \& Fried MW 2003 Current therapy for hepatitis C: pegylated interferon and ribavirin. Clinics in Liver Disease 7 149-161.

McHutchison JG, Gordon SC, Schiff ER, Shiffman ML, Lee WM, Rustgi VK, Goodman ZD, Ling MH, Cort S \& Albrecht JK 1998 Interferon alfa-2b alone or in combination with ribavirin as initial treatment for chronic hepatitis C. Hepatitis Interventional Therapy Group. New England Journal of Medicine 339 1485-1492.

Montor JM, Mendoza ME \& Romano MC 1998 Effect of human and murine interferon-alpha on steroid production by rat ovarian cells. Life Sciences 62 1733-1744.

Soto Alvarez J, Sacristan JA \& Alsar MJ 1991 Interferon alfa-2a-induced impotence. DICP, The Annals of Pharmacotherapy 25 1397.

Spollen JJ 3rd, Wooten RG, Cargile C \& Bartztokis G 2004 Prolactin levels and erectile function in patients treated with risperidone. Journal of Clinical Psychopharmacology 24 161-166.

SPSS 2002 SPSS für Windows 11·5·1. Chicago, IL: SPSS Inc.

Vermeulen A, Verdonck L \& Kaufman JM 1999 A critical evaluation of simple methods for the estimation of free testosterone in serum. Journal of Clinical Endocrinology and Metabolism 84 3666-3672.

Weidinger SE, Hein R, Ring J \& Kohn FM 2002 Endocrinologic changes in male patients with melanoma during interferon alfa- $2 \mathrm{~b}$ therapy. Archives of Dermatology 138 541-542.

Received 28 January 2005

Accepted 23 February 2005 